\title{
HUBUNGAN DUKUNGAN KELUARGA DENGAN KEPATUHAN MINUM OBAT PADA LANSIA PENDERITA HIPERTENSI
}

\author{
Devi Widyaningrum ${ }^{1)}$, Dwi Retnaningsih ${ }^{2}$, Tamrin ${ }^{3 /}$ \\ STIKES Widya Husada Semarang, Jln Subali Raya No 12, Kraprak, Semarang Barat \\ Email : deviwningrum14@gmail.com
}

\begin{abstract}
ABSTRAK
Latar Belakang : Dukungan keluarga merupakan suatu sifat yang mendukung dan selalu memberikan pertolongan serta bantuan jika diperlukan oleh salah satu dari anggota keluarga. Bentuk dari dukungan keluarga berupa informasi, penilaian, instrumental, dan emosional.Menurut catatan dari Profil Kesehatan Jawa Tengah tahun 2017, jumlah pasien penderita hipertensi sebanyak 8355 jiwa. Dukungan keluarga juga mempengaruhi terjadinya kepatuhan minum obat pada pasien dengan hipertensi. Tujuan penelitian ini untuk mengetahui hubungan dukungan keluarga dengan kepatuhan minum obat pada lansia penderita hipertensi di wilayah Puskesmas Gayamsari Kota Semarang.

Metodelogi Penelitian : Penelitian ini menggunakan penelitian kuantitatif dengan metode deskriptif korelasi dengan pendekatan cross sectional dan instrument penelitian dengan menggunakan kusioner. Teknik sampel yang digunakan adalah Teknik Purposive Sampling. Populasi dengan jumlah 210 lansia penderita hipertensi dan jumlah sampel 137 lansia penderita hipertensi. Analisa data yang digunakan yaitu uji Rank Spearman.

Hasil : Hasil dari penelitian ini didapatkan dari 62 lansia responden terdapat dukungan keluarga baik, 46 (33,6\%) mempunyai kepatuhan minum obat yang tinggi dan 15 lansia mendapat dukungan keluarga kurang, 15 (10,9\%) mempunyai kepatuhan minum obat yang sedang. Hasil uji statistik Spearman Rho menunjukkan bahwa nilai $\rho$ value $0,000 \leq \alpha 0,05$. Koefisiensi korelasi 0,874 yang artinya terdapat hubungan dukungan keluarga dengan kepatuhan minum obat pada lansia penderita hipertensi di Wilayah Puskesmas Gayamsari Kota Semarang adalah sangat kuat.

Kesimpulan : Ada hubungan dukungan keluarga dengan kepatuhan minum obat pada lansia penderita hipertensi di wilayah Puskesmas Gayamsari Kota Semarang.
\end{abstract}

Kata Kunci : Dukungan keluarga, Kepatuhan minum obat, Lansia

\begin{abstract}
Background: Family support a trait that supportive and always provides help and assistance if needed by one of the family members. Form of family support in the form of information, assessment, instrumental, and emotional. According to records from the Health Profile of Central Java in 2017, the number of patients with hypertension was 8355 people. Family support also affects the occurrence of medication adherence in patients with hypertension. The purpose of this study was to determine the relationship of family support with medication adherence in elderly people with hypertension in the Gayamsari Community Health Center in Semarang.

Research Methodology: This study uses quantitative research with a descriptive correlation method with a cross sectional approach and research instruments using questionnaires. The sample technique used Purposive Sampling Technique. The population 210 elderly and the sample 137 elderly. Analysis of the data used is the Spearman Rank test. Results: The results of this study were obtained from 62 elderly respondents with good family support, $46(33,6 \%)$ had high medication adherence and 15 elderly received less family support, 15 (10,9\%) had moderate medication adherence. Spearman Rho statistical test results showed that $\rho$ value 0,000 $\leq \alpha$ 0,05. Correlation coefficient 0,874 which means there is a relationship of family support with medication adherence in elderly people with hypertension in the Gayamsari Community Health Center in Semarang city very strong.

Conclusion: There is a relationship of family support with medication adherence in elderly patients with hypertension in the Gayamsari Community Health Center in Semarang.
\end{abstract}

Keywords: Family Support, Compliance with medication, Elderly 


\section{PENDAHULUAN}

Lansia merupakan proses akhir dari perkembangan manusia. Proses akhir perkembangan ditandai dengan penurunan sistem kardiovaskuler. Salah satu masalah yang dihadapi lansia pada penurunan fungsi kardiovaskuler adalah hipertensi (Azmi, Karim, Nauli, 2018). Hipertensi pada lansia terjadi karena adanya penebalan pada dinding arteri yang mengakibatkan penumpukan zat kolagen pada lapisan otot, sehingga pembuluh darah berangsur-angsur mengalami penyempitan dan menjadi kaku. Penyempitan pada sistem peredaran darah mengakibatkan kenaikan tekanan darah diatas nilai normal yaitu tekanan sistolik $\geq 140 \mathrm{mmHg}$ sedangkan tekanan diastolik $\geq 90 \mathrm{mmHg}$ (Novitaningtyas, 2014). Hipertensi pada lansia merupakan penyakit kronis yang disebut juga dengan pembunuh gelap (silent killer) karena termasuk dalam kategori penyakit yang mematikan tanpa disertai dengan gejala-gejala terlebih dahulu sebagai peringatan bagi korbannya. Jika gejala tersebut muncul, seringkali dianggap gangguan biasa oleh penderita, sehingga penderita terlambat menyadari akan datangnya dampak penyakit hipertensi yang berkembang dari tahun ke tahun sehingga menyebabkan komplikasi (Merdikoputro, 2014). Prevalensi hipertensi di Indonesia tercatat sebanyak 8355 jiwa, penderita hipertensi berdasarkan usia lanjut usia ( $\geq 60$ tahun) sebanyak 7413 jiwa. Upaya yang telah dilakukan untuk menangani kasus hipertensi yaitu mengaktifkan kegiatan posbindu, pemeriksaan tekanan darah di pelayanan kesehatan terdekat dan pemberian obat penurun tekanan darah (Profil Kesehatan Jawa Tengah, 2017). Dari data hasil rekapitulasi Penyakit Hipertensi puskesmas kota Semarang tahun 2017 menunjukkan bahwa Puskesmas Gayamsari merupakan puskesmas dengan rate kasus tertinggi yaitu 8,56\% dan selalu mengalami kenaikan jumlah kasus-kasus baru pada tahun 2015-2017. Pada tahun 2015 terdapat 1651 kasus baru, tahun 2016 naik 2\% menjadi 1682 kasus baru dan pada tahun 2017 terjadi peningkatan lagi sebesar 13\% menjadi 1940 kasus baru (Puskesmas Gayamsari, 2017). Lansia dengan penyakit hipertensi memiliki masalah besar pada kepatuhan minum obat, derajat dimana lansia mengikuti anjuran klinis dari dokter yang memberi obat untuknya. Dalam hal ini dukungan keluarga merupakan faktor penting dalam membantu individu dalam menyelesaikan masalah pada lansia. Dukungan keluarga yang didapatkan lansia akan menambah rasa percaya diri dan menambah motivasi untuk menghadapi masalah dan meningkatkan kepuasan hidup, dukungan ini berupa pemberian motivasi, dukungan ekonomi serta kesediaan mengingatkan atau menyiapkan obat yang akan diminum oleh lansia penderita hipertensi (Niman, 2017). Dukungan keluarga berpengaruh pada kepatuhan minum obat penderita hipertensi. Pengobatan pasien yang tidak lengkap disebabkan oleh peranan anggota keluarga yang tidak sepenuhnya mendampingi penderita, akibatnya penyakit hipertensi yang diderita kambuh kembali. Kepatuhan dalam pengobatan akan meningkat ketika penderita mendapat bantuan dari keluarga. Di samping itu, penderita yang tidak memiliki keluarga atau tidak ada suportif dari keluarga akan mempengaruhi terminasi pengobatan lebih awal dan hasil tidak memuaskan (Desy, 2014).

Berdasarkan fenomena tersebut peneliti tertarik untuk melakukan penelitian terkait "Hubungan dukungan keluarga dengan kepatuhan minum obat pada lansia penderita hipertensi di wilayah Puskesmas Gayamsari Kota Semarang".

\section{METODE PENELITIAN}

Metode yang digunakan adalah cross sectional yaitu peneliti mengukur atau mengumpulkan datanya dan dilakukan dalam satu waktu secara bersamaan. Populasi dalam penelitian ini lansia yang memiliki penyakit hipertensi sebanyak 137 lansia yang melakukan pemeriksaan di puskesmas gayamsari kota semarang. Pada penelitian ini teknik yang digunakan non probability sampling yaitu teknik purposive sampling yaitu teknik penentuan sampel dengan pertimbangan tertentu.

\section{HASIL DAN PEMBAHASAN}

Gambaran Umum Lokasi Penelitian Puskesmas Gayamsari Kota Semarang memliki luas wilayah 750,15 ha yang terletak di Jl.Slamet Riyadi No.4 A Semarang, Jawa Tengah.

\section{Karakteristik Responden}

Tabel 1. Distribusi frekuensi responden berdasarkan jenis kelamin.

\begin{tabular}{llc}
\hline Jenis Kelamin & Frek & Presentase \\
\hline Laki-laki & 36 & 26,27 \\
Perempuan & 101 & 73,72 \\
\hline
\end{tabular}

Berdasarkan tabel 1 hasil penelitian pada karakteristik jenis kelamin menunjukkan bahwa sebanyak 101 lansia $(73,7 \%)$ berjenis kelamin perempuan dan sebanyak 36 lansia $(26,3 \%)$ berjenis kelamin laki-laki. Pada penelitian ini mayoritas yang paling banyak berjenis kelamin perempuan sebanyak 101 lansia (73,7\%). Hal ini dikarenakan adanya masalah hormonal. Pada wanita lansia yang mayoritas sudah mengalami menopause terdapat hormon progesteron yang lebih banyak daripada hormon esterogen. Hormon progesteronlah yang memicu peningkatan tekanan darah Kusumawaty (2016).

Tabel 2. Distribusi frekuensi responden berdasarkan riwayat pendidikan.

\begin{tabular}{lll}
\hline Tingkat Pendidikan & Frek & Presentase \\
\hline Tidak tamat SD & 6 & 4,37 \\
SD & 16 & 11,67 \\
SMP & 35 & 25,54 \\
SMA & 72 & 52,55 \\
Perguruan Tinggi & 8 & 5,83 \\
\hline
\end{tabular}

Berdasarkan tabel 2, karakteristik responden berdasarkan riwayat pendidikan menunjukkan bahwa sebanyak 6 lansia $(4,4 \%)$ tidak tamat SD, sebanyak 17 lansia $(12,4 \%)$ tingkat pendidikan terakhir SD, sebanyak 34 lansia $(24,8 \%)$ penderita terakhir SMP, 72 $(52,6 \%)$ lansia pendidikan terakhir SMA dan sebanyak 8 lansia $(5,8 \%)$ lansia terakhir Perguruan Tinggi. Pada penelitian ini mayoritas yang paling banyak pendidikan 
terakhir SMA sebanyak 72 lansia $(52,6 \%)$. Hal ini menunjukkan bahwa program pendidikan efektif dalam meningkatkan pengetahuan, meningkatkan manajemen diri, dan mengendalikan kebiasaan gaya hidup yang merugikan pasien dengan hipertensi. Pendidikan juga sangat berpengaruh tentang hipertensi terhadap peningkatan pengetahuan mengelola hipertensi Beigi, et al., (2014).

Tabel 3. Distribusi frekuensi responden berdasarkan riwayat pekerjaan

\begin{tabular}{lll}
\hline Riwayat Pekerjaan & Frek & Persentase \\
\hline PNS & 10 & 7,29 \\
Swasta & 35 & 25,54 \\
Wirausaha & 37 & 27,00 \\
\hline Tidak Bekerja & 55 & 40,14 \\
\hline
\end{tabular}

Berdasarkan tabel 3 hasil penelitian pada karakteristik responden dengan riwayat pekerjaan menunjukkan bahwa sebanyak 10 lansia $(7,3 \%)$ memiliki riwayat pekerjaan PNS, sebanyak $35(25,5 \%)$ dengan riwayat pekerjaan swasta, sebanyak 37 lansia $(27,0 \%)$ dengan riwayat pekerjaan wirausaha dan sebanyak 55 lansia $(40,1 \%)$ menyatakan bahwa tidak bekerja. Pada penelitian ini mayoritas yang paling banyak tidak bekerja sebanyak 55 lansia $(40,1 \%)$. Hal ini menunjukkan bahwa pekerjaan sangat berpengaruh terhadap penderita hipertensi lansia karena fisiknya sudah mulai melemah dan lansia sudah tidak mampu dalam cekatan beraktifitas.Menurut Livana, dkk (2018) menyatakan bahwa volume pekerjaan lansia lebih sedikit dibandingkan pekerjaan orang muda. Sehubungan dengan itu, menurut Maryam (2011) juga menyatakan proses degenerative menyebabkan terjadinya penurunan fungsi organ-organ tubuh karena kerusakan sel-sel akibat proses menua, sehingga menjadikan populasi lansia rentan terhadap perubahanperubahan kehidupan terkait dengan biologi atau fikiran fisik dan tidak produktif lagi.

Tabel 4. Distribusi Frekuensi Responden Berdasarkan Dukungan Keluarga

\begin{tabular}{lll}
\hline $\begin{array}{l}\text { Dukungan } \\
\text { Keluarga }\end{array}$ & Jumlah & $\begin{array}{l}\text { Presentase } \\
(\%)\end{array}$ \\
\hline Baik & 62 & 45,3 \\
Cukup & 60 & 43,8 \\
Kurang & 15 & 10,9 \\
\hline Total & 137 & $100 \%$ \\
\hline
\end{tabular}

Berdasarkan tabel 4 diketahui hasil penelitian yang telah dilakukan menunjukkan bahwa sebagian besar responden mendapat dukungan keluarga berkategori baik berjumlah 62 lansia $(45,3 \%)$ sedangkan 60 lansia $(43,8 \%)$ yang mendapat dukungan keluarga berkategori cukup dan yang terakhir 15 lansia $(10,9 \%)$ mendapat dukungan keluarga berkategori kurang. Dari hasil tersebut diketahui bahwa lansia yang paling banyak mendapatkan dukungan keluarga dengan kategori baik sebanyak 62 lansia $(45,3 \%)$. hal tersebut menunjukkan bahwa responden lansia merasa mendapatkan perhatian dari keluarganya, responden lansia merasa disayangi, dicintai dan dihormati oleh anggota keluarganya.

Dukungan keluarga dinyatakan baik jika lansia merasa mendapat bantuan, simpati dan empati yang diberikan oleh keluarga kepadanya baik berupa barang, jasa, informasi, nasehat, yang mana membuat lansia merasa, disayang, dicintai, dihargai dan memiliki semangat atau motivasi untuk selalu sehat. Hal ini diperkuat dengan penelitian yang dilakukan oleh Ningrum (2018) yang menyatakan bahwa masih berfungsinya keluarga untuk memperhatikan, menghargai, mencintai, dan membantu berupa materi, informasi, instrument atau bantuan secara langsung dan berupa pujian atas keberhasilan yang dicapai oleh responden.

Penyakit kronis seperti hipertensi membutuhkan pengobatan seumur hidup. Hal ini merupakan tantangan bagi lansia yang mengalami hipertensi serta keluarga agar dapat mempertahankan motivasi untuk mematuhi pebgobatan selama bertahun-tahun. Salah satu meningkatkan motivasi adalah melalui dukungan keluarga (Osamor, 2015). Dukungan keluarga dapat dilakukan dengan memberi motivasi, mengingatkan dalam hal minum obat, mendengarkan lansia dalam bercerita, menyediakan biaya pengobatan, mengawasi lansia dalam meminum obat. Dukungan dari keluarga membuat penderita tidak merasa terbebani dengan penyakit yang dideritanya. Dukungan keluarga sebagai suatu koping keluarga dalam menghadapi masalah salah satu anggota keluarganya, sehingga keluarga dapat meningkatkan semangat dan motivasi untuk berperilaku sehat (Irnawati, 2016).

Tabel 5. Distribusi Frekuensi Responden Berdasarkan Kepatuhan Minum Obat

\begin{tabular}{lll}
\hline $\begin{array}{l}\text { Kepatuhan } \\
\text { Minum Obat }\end{array}$ & Jumlah & Presentase \\
\hline Tinggi & 53 & 38,7 \\
Sedang & 84 & 61,3 \\
Rendah & 0 & 0 \\
\hline Total & 137 & $100 \%$ \\
\hline
\end{tabular}

Berdasarkan tabel 5 diketahui hasil penelitian kepatuhan minum obat pada lansia penderita hipertensi sebanyak 53 lansia $(38,7 \%)$ sedangkan 84 lansia $(61,3 \%)$ dan kepatuhan minum obat berkategori sedang dan yang terakhir tidak terdapat lansia yang memiliki kategori kepatuhan minum obat rendah. Pada penilitian ini mayoritas kepatuhan minum obat dalam kategori sedang sebanyak 84 lansia (61,3\%). Hal itu diartikan bahwa responden membutuhkan keluarga untuk sekedar mengingatkan, menyimpan atau mengawasi responden dalam waktu minum obat.

Menurut Niven (2013) dalam Ningrum (2018) mengatakan bahwa salah satu faktor yang menyebabkan ketidakpatuhan dalam minum obat yaitu sebagian besar pasien tidak memahami instruksi yang diberikan, karena kegagalan professional kesehatan dalam memberikan informasi yang lengkap, penggunaan istilah-istilah medis dan banyaknya instruksi yang harus diingat oleh pasien. Hal ini diperkuat oleh Susanto (2015) bahwa kurangnya pemahaman pasien tentang hipertensi dan tujuan terapi hipertensi dapat mempengaruhi kepatuhan pasien dalam pengobatan hipertensi. 


\section{Analisa Bivariat}

Tabel 7. Hubungan Dukungan Keluarga dengan Kepatuhan Minum Obat pada Lansia Penderita Hipertensi di Wilayah Puskesmas Gayamsari Kota Semarang

\begin{tabular}{|c|c|c|c|c|c|c|c|c|c|c|}
\hline \multirow{3}{*}{$\begin{array}{l}\text { Dukungan } \\
\text { Keluarga }\end{array}$} & \multicolumn{10}{|c|}{ Kepatuhan Minum Obat } \\
\hline & \multicolumn{2}{|c|}{ Tinggi } & \multicolumn{2}{|c|}{ Sedang } & \multicolumn{2}{|c|}{ Rendah } & \multirow[t]{2}{*}{ Total } & \multirow[t]{2}{*}{$\%$} & \multirow[t]{2}{*}{ P Value } & \multirow[t]{2}{*}{ Rho } \\
\hline & Frek & $\%$ & Frek & $\%$ & Frek & $\%$ & & & & \\
\hline Baik & 46 & 74,2 & 16 & 25,8 & 0 & 0 & 62 & 100 & & \\
\hline Cukup & 7 & 11,7 & 53 & 88,3 & 0 & 0 & 60 & 100 & 0,000 & 0,874 \\
\hline Kurang & 0 & 0,0 & 15 & 100,0 & 0 & 0 & 15 & 100 & & \\
\hline Total & 53 & 38,7 & 84 & 61,3 & 0 & 0 & 137 & $100 \%$ & & \\
\hline
\end{tabular}

Hasil penelitian menunjukkan bahwa dari 137 lansia di

Hubungan Dukungan Keluarga dengan Kepatuhan Minum Obat pada Lansia Penderita Hipertensi di Wilayah Puskesmas Gayamsari Kota Semarang

Berdasarkan hasil penelitian menunjukkan bahwa hasil uji statistic dengan $p$ value $<\alpha$ yang berarti $(0,000$ $<0,05)$ sehingga dapat disimpulkan ada hubungan dukungan keluarga dengan kepatuhan minum obat pada lansia penderita hipertensi di Wilayah Puskesmas Gayamsari Kota Semarang (Ha diterima Ho ditolak).

Hasil penelitian menunjukkan bahwa dari 137 lansia di wilayah Puskesmas Gayamsari Kota Semarang diantaranya 62 lansia memiliki dukungan keluarga baik dengan kepatuhan minum obat tinggi sebanyak 46 lansia (74,2\%), dukungan keluarga baik dengan kepatuhan minum obat sedang sebanyak 16 lansia $(25,8 \%)$ dan tidak ada lansia yang memiliki dukungan keluarga baik dengan kepatuhan minum obat rendah.

Hal ini dikarenakan lansia merasa mendapat bantuan, simpati dan empati yang diberikan oleh keluarga kepadanya baik berupa barang, jasa, informasi, nasehat, yang mana membuat lansia merasa, disayang, dicintai, dihargai dan memiliki semangat atau motivasi untuk selalu sehat. Pernyataan ini diperkuat oleh Ningrum (2018) yang menyatakan bahwa masih berfungsinya keluarga untuk memperhatikan, menghargai, mencintai, dan membantu berupa materi, informasi, instrument atau bantuan secara langsung dan berupa pujian atas keberhasilan yang dicapai oleh responden.

Hasil penelitian menunjukkan bahwa dari 137 lansia di wilayah Puskesmas Gayamsari Kota Semarang diantaranya 60 lansia memiliki dukungan keluarga cukup dengan kepatuhan minum obat tinggi sebanyak 7 lansia $(11,7 \%)$, dukungan keluarga cukup dengan kepatuhan minum obat sedang sebanyak 16 lansia $(25,8 \%)$, dan tidak terdapat lansia dengan dukungan keluarga cukup dan kepatuhan minum obat rendah. Hal ini dikarenakan lansia merasa tenang dan bahagia karena meskipun keluarga sibuk bekerja tetapi masih memberi bantuan berupa materi, barang atau jasa, dan secara emosional. Pernyataan ini diperkuat dengan penelitian yang dilakukan oleh Yeni (2016) menyatakan bahwa karena adanya dukungan keluarga yang diberikan baik itu dukungan emosional, penghargaan, instrumental maupun informasional yang dapat membuat penderita mengikuti ketentuan terapi yang sudah ditetapkan. wilayah Puskesmas Gayamsari Kota Semarang diantaranya 15 lansia tidak memiliki dukungan keluarga kurang dengan kepatuhan minum obat tinggi, dan terdapat 15 lansia (100\%) memiliki dukungan keluarga kurang dengan kepatuhan minum obat sedang serta tidak terdapat lansia yang memiliki dukungan keluarga kurang dengan kepatuhan minum obat yang rendah.

Hal ini dikarenakan lansia merasa tidak diperhatikan, tidak diberi kasih sayang dan pengertian dikarenakan ekonomi yang kurang sehingga keluarga kurang mampu memenuhi kebutuhan lansia ataupun dikarenakan kesibukan keluarga dalam bekerja sehingga mengabaikan dan kurang peduli dengan apa yang terjadi oleh lansia. Pernyataan ini diperkuat oleh Utami (2016) yang menyatakan bahwa penderita hipertensi yang tidak memperoleh dukungan keluarga seperti perhatian, kasih sayang, dukungan penghargaan yang positif, dan dukungan secara financial akan merasa dirinya tidak berguna dan cenderung untuk tidak mengikuti nasehat atau saran dari tenaga medis.

Berdasarkan hasil penelitian sebelumnya yang dilakukan oleh Ningrum (2018) dalam judul Hubungan Dukungan Keluarga dengan Kepatuhan Minum Obat Pasien Hipertensi di Puskesmas Seyegan Sleman Yogyakarta, menyatakan bahwa terdapat dukungan keluarga dengan kategori baik dan kepatuhan minum obat dengan kategori sedang serta masih berfungsinya keluarga untuk memberi perhatian, menghargai dan mencintai anggota keluarga yang sakit. Dari penelitian tersebut maka ditemukan adanya hubungan dukungan keluarga dengan kepatuhan minum obat pada penderita hipertensi. Hasil analisis menunjukkan $\rho$ value $0,000 \quad(\rho<0,05)$ dan koefisien korelasi sebesar 0,426. Hasil analisis tersebut menunjukkan bahwa semakin baik dukungan keluarga yang didapatkan oleh penderita hipertensi maka dalam menjalankan kepatuhan minum obat pada hipertensi juga akan semakin baik. 


\section{SIMPULAN}

1. Dukungan keluarga pada lansia penderita hipertensi di wilayah Puskesmas Gayamsari Kota Semarang menunjukkan bahwa lansia hipertensi dengan kategori dukungan keluarga baik sebanyak 62 lansia $(45,3 \%)$ dukungan keluarga cukup sebanyak 60 lansia $(43,8 \%)$, dan dukungan keluarga kurang sebanyak 15 lansia (10,9\%).

2. Kepatuhan minum obat pada lansia penderita hipertensi di wilayah Puskesmas Gayamsari Kota Semarang menunjukkan bahwa lansia hipertensi dengan kategori kepatuhan minum obat tinggi sebanyak 53 lansia $(38,7 \%)$ dan kepatuhan minum obat sedang sebanyak 84 lansia (61,3\%).

3. Ada hubungan dukungan keluarga dengan kepatuhan minum obat pada lansia penderita Hipertensi di wilayah Puskesmas Gayamsari Kota Semarang dengan nilai $\rho$ value $0,000<\alpha$ 0,0. Maka Ha diterima dan Ho ditolak.

\section{SARAN}

1. Bagi Pelayanan Kesehatan (perawat) di Puskesmas Gayamsari

Saran yang peneliti ajukan untuk Perawat Puskesmas Gayamsari agar dapat meningkatkan pelayanan serta memberikan informasi dan motivasi secara kontinue kepada lansia penderita hipertensi tentang kepatuhan atau ketaatan dalam mengkonsumsi obat hipertensi.

2. Bagi Institusi Pendidikan

Saran yang peneliti ajukan untuk Institusi Pendidikan Stikes Widya Husada Semarang yaitu diharapkan agar dapat menggunakan hasil penelitian ini sebagai referensi dan bahan tolok ukur untuk melakukan penelitian.

3. Bagi Keluarga

Saran dari peneliti untuk keluarga yang memiliki lansia dengan hipertensi hendaknya lebih dapat meluangkan waktu untuk mengawasi saat minum obat, serta keluarga dapat meluangkan waktu untuk mendengarkan cerita, keluh kesah, dan memberi respon terhadap apa yang diceritakan oleh lansia tersebut. Karena dengan cara itu lansia dapat merasa dirinya masih disayangi, dicintai, dibutuhkan dan dihargai oleh keluarganya.

4. Bagi Peneliti Selanjutnya

Saran yang diajukan untuk peneliti selanjutnya diharapkan dapat melakukan penelitian lanjutan mengenai Hubungan dukungan keluarga dengan kepatuhan minum obat pada lansia penderita hipertensi dan serta dapat memeriksa tekanan darah lansia serta dapat mengganti dengan metode kualitatif guna mengetahui lebih lanjut tentang dukungan keluarga dan dampak yang dirasakan oleh responden.

5. Bagi Peneliti

Penelitian ini dibuat guna untuk mengetahui adanya hubungan dukungan keluarga dengan kepatuhan minum obat pada lansia penderita hipertensi dan syarat untuk memenuhi lulus sarjana keperawatan serta mengembangkan tugas keperawatan khususnya keperawatan gerontik.

\section{DAFTAR PUSTAKA}

Azmi, Nur., Karim, Darwin., Nauli, F.A. (2018). Gambaran Kualitas Hidup Lansia Dengan Hipertensi Di Wilayah Kerja Puskesmas Sidomulyo Kecamatan Tampan Pekanbaru. Diakses pada bulan Mei 2019.

Beigi, M.A., Zibaeenezad M.J., Aghasadeghi K., Aghasadeghi, K., Jokar, A., Shekarforoush, S., \& Khazraei, H. (2014). The effect of educational program on hypertension management. International Cardiovascular Research Journal, 8(3) 94-98.

Desy, F.M. (2014). Hubungan Antara Dukungan Keluarga Dan Kepatuhan Minum Obat Pada Penderita Tuberkulosis Di Wilayah Ciputat Tahun 2014. Diakses pada bulan Mei 2019.

Irnawati, N, M. (2016) Pengaruh Dukungan Keluarga Terhadap Kepatuhan Minum Obat Pada Penderita Tuberkulosis Di Puskesmas Metoboi Kecil Kota Kotamobagu. Jurnal Kedokteran Komunitas dan Tropik, IV (1), 59-64.

Kusumawaty, dkk. (2016). Hubungan Jenis Kelamin dengan Intensitas Hipertensi pada Lansia di Wilayah Kerja Puskesmas Lakbok Kabupaten Ciamis. http://journal.umy.ac.id/index.php/mm/articl e/view/4450. Diakses pada tanggal 10 Agustus 2019.

Livana, dkk. (2018). Gambaran Tingkat Depresi Lansia. http://jki.ui.ac/index.php/jki/article/view/464 . Diakses pada tanggal 5 Agustus 2019.

Maryam, dkk. (2011). Mengenal Usia Lanjut dan Perawatannya. Jakarta : Salemba Medika.

Merdikoputro, Djoko. (2014). Hubungan Dukungan Keluarga Dengan Kepatuhan Berobat Pada Pasien Hipertensi Di Puskesmas Dau Kabupaten Malang. Diakses pada Mei 2019.

Niman, Sisilia., Hariyanto, Tanto., Dewi, Novita. (2017). Hubungan Antara Dukungan Keluarga Dengan Fungsi Sosial Lansia Di Wilayah Kelurahan Tlogomas Kecamatan Lowokwaru Malang. Diaksaes pada Mei 2019.

Novitaningtyas, T. (2014). Hubungan karakteristik (umur, jenis kelamin, tingkat pendidikan) dan aktivitas fisik dengan tekanan darah pada lansia di kelurahan makamhaji kecamatan kartasura kabupaten sukoharjo. Diakses pada Mei 2019.

Osamor, P.E. (2015) Social support and management of hypertension in South-Nigeria. Cardiovascular Journal of Africa, 26 (1), 29-33.

Puskesmas Gayamsari, Profil Puskesmas Tahun 2018, 
(2018), Semarang; Puskesmas Gayamsari.

Rahayu, Minarti. (2013). Dinamika Strategik Wirausahawan Tionghwa. Malang : UB Press.

Sugiyono. (2018). Metode Penelitian Kuantitatif. Bandung : Alfabeta.

Susanto, Y. (2015). Hubungan Dukungan Keluarga Dengan Kepatuhan Minum Obat Pasien Hipertensi Lansia Di Wilayah Kerja Puskesmas Sungai Cuka Kabupaten Tanah Laut. Jurnal Ilmiah Manuntung, 1(1), 62-67.

Trijono, Rachmat. (2015). Metode Penelitian Kuantitatif. Jakarta : Papas Sinar Sinanti.

Utami, Sri. 2016. Hubungan Dukungan Sosial Keluarga dengan Kepatuhan Berobat Penderita Hipertensi di Puskesmas Tualang. http://ejournal.uin-

suska.ac.id/index.php/psikologi/article/view/ 3235. Diakses pada tanggal 10 Agustus 2019.

Yeni, Fitra, dkk. (2016). Dukungan Keluarga Mempengaruhi Kepatuhan Pasien Hipertensi.

http://jki.ui.ac.id/index.php/jki/article/view/4 71. Diakses pada tanggal 8 Agustus 2019. 